\section{As Ações Afirmativas por Critério Étnico- -Racial no Ensino Superior Brasileiro: Análise Antropológica e Jurídica}

\section{Resumo}

Trata-se de um trabalho que busca analisar a questão das ações afirmativas no ambiente universitário brasileiro. Procurou-se dialogar entre a antropologia e a técnica jurídica de maneira a apresentar as justificativas, argumentos e resultados das políticas de ações afirmativas no Brasil, desde diferentes pontos de vista. Este artigo apresenta e discute, ainda, argumentos e estatísticas sobre o assunto, de maneira a proporcionar ao leitor/pesquisador uma visão mais aprofundada sobre o tema.

Palavras-Chave: Quotas, Ações Afirmativas, Étnico-racial, Ensino e Superior.

\section{Abstract}

This paper seeks to analyze the issue of affirmative actions in the Brazilian university environment. We sought to dialogue between anthropology and legal technique in order to present the justifications, arguments and results of affirmative action policies in Brazil, from different points of view. Arguments and statistics on the subject are presented and discussed in order to provide the reader / researcher with a deeper insight into the subject.

Keywords: Affirmative Actions, Ethnic-Racial, University and College.

\section{Introdução}

Este artigo aborda de maneira distinta a questão das ações afirmativas por critério étnico-racial no ensino superior brasileiro. A permanente atualidade do tema decorre não apenas da necessidade de reavaliar-se a farta e excelente produção doutrinária,
Antônio Augusto

Bonatto Barcellos

Pesquisador no Instituto de

Iberoamérica USAL.

\section{Bruno Fontes Corrêa}

Barcellos \& Correa Advogados Associados. 
mas também de verificar-se a eficácia social dos instrumentos jurídico-políticos disponíveis.

O presente estudo faz uma análise da temática sob aspectos socioculturais e jurídicos. Partindo de uma contextualização da questão racial brasileira desde sua conformação histórica, são revisados dados e estatísticas oficiais na tentativa de melhor delinear o objeto da investigação. A partir dessa perspectiva e renunciando desde logo ao esgotamento do tema, há um enfrentamento às críticas colacionadas em âmbito acadêmico no tocante ao sistema de reserva de vagas para acesso ao ensino superior com base no critério racial. Por fim, na tentativa de procurar as respostas para indagação em torno da efetividade das medidas de ação afirmativa, há uma análise, ainda que superficial, de alguns resultados até então obtidos nas universidades brasileiras.

\section{Contextualização das Relações Sociais no Brasil}

\section{Aspectos teórico-históricos}

Antes de se traçar um panorama sobre as relações sociais no Brasil, é necessário fazer um breve enfoque histórico. A análise desde o período escravocrata, por certo, permitirá ao leitor o estabelecimento de uma relação conectiva entre o desenvolvimento do país e o comportamento discriminatório afeito à realidade brasileira.

O regime de escravidão perdurou por mais de três séculos no país e, ao longo dessa convivência, cerca de 5.220.054 de africanos escravizados entraram no Brasil. A abolição da escravidão, além de tardia (13 de maio de 1888), não teve entre seus fundamentos um viés humanitário ou social. Na verdade, a lei emancipadora apenas legitimou uma realidade, uma vez que a liberdade já havia sido, de fato, conquistada pelos negros (BASTIDE \& FERNANDES, 1955). Não há de se olvidar, ainda, que a iniciativa legislativa partiu justamente de um gabinete de conservadores, liderado por fazendeiros, eis que já convencidos de que, além de inevitável, o trabalho livre reduziria custos e aumentaria a eficiência. Além disso, esses fazendeiros pretendiam comandar a abolição e, por consequência, assumir o controle do governo. Isso tudo com o objetivo principal de impedir medidas mais radicais, especialmente a reforma agrária (SKIDMORE, 1976).

Seguindo essa linha de raciocínio, é de se esperar que a abolição da escravidão não se fez acompanhar por medidas de assistência e garantia, sobretudo voltadas à inserção dos libertos à vida em sociedade, como uma reforma agrária ou mecanismos de acesso ao ensino e ao mercado de trabalho. O desfecho não fugiu à lógica e, então, os negros foram alçados as mais precárias condições de vida, bem como parcialmente eliminados do sistema de trabalho (SANTOS, 1999).

Enquanto as oportunidades foram aproveitadas por imigrantes e nacionais brancos, os negros apenas lutavam pela reabsorção a partir das piores e mal remuneradas ocupações. Desde então, em virtude dessa igualdade jurídica decorrente da abolição, surge uma nova classificação hierárquica no seio da sociedade, agora não mais entre escravos e homens livres, mas sim entre negros e brancos, e, portanto, mesmo após abolição, o negro foi mantido como vítima de preconceito e discriminação (CARDOSO, 1997). Enfim, esse é panorama social que nos foi legado pelo regime escravocrata.

Com a abolição da escravidão e o fim da Monarquia, a questão racial ganhou relevância. Foram introduzidas clássicas teorias raciais que legitimavam a desigualdade através de fundamentos biológicos, sem, contudo, assentir com a ideia de que a mestiçagem provocaria uma degeneração, uma particularidade brasileira. Segundo Skidmore (1976), prevaleceu aqui a corrente de entendimento no sentido de que seria possível acabar com a questão racial por meio de um processo de "branqueamento". Com essa finalidade, então, no final do Império, o país passou a fomentar o processo imigratório de brancos. 
Outro aspecto que merece referência é que, no Brasil, após a abolição, em vez de se estabelecer ideologias raciais oficiais e categorias de segregação, como o apartheid na África do Sul, criou-se a imagem de uma democracia racial (SCHWARCZ, 1998). Cuida-se aqui da tese inaugurada no Brasil por Gilberto Freyre, a qual faz uma distinção entre raça e cultura, reconhecendo o valor do negro, do português e do índio.

Em outras palavras, Gilberto Freyre em suas obras apresenta um novo retrato do Brasil, no qual se revela uma sociedade heterogênea e harmônica, dando outro significado à miscigenação. Em Casa-Grande \& Senzala, Freyre ressalta: "Todo brasileiro, mesmo o alvo, de cabelo louro, traz na alma, quando não na alma e no corpo, a sombra, ou pelo menos a pinta, do indígena ou do negro" (FREYRE, 1992, p. 307).

Torna-se necessário, por derradeiro, a advertência de que a suposta democracia racial passou a ser afastada no início da década de 1950, notadamente a partir de pesquisas realizadas através de um projeto financiado pela Unesco, que acreditava ser a experiência brasileira um modelo no tocante ao preconceito racial, razão pela qual poderia inspirar outras nações. De fato, o bom convívio entre diferentes etnias foi identificado e sustentado por alguns dos pesquisadores. Entretanto, outros, a exemplo de Roger Bastide e Florestan Fernandes, revisaram os modelos assentados e, em sentido contrário, apontaram rastros de discriminação e preconceito.

\section{A Desigualdade racial no Brasil}

Desde a antiguidade se mantém um interesse em classificar as pessoas. E, no decorrer dos anos, isso passou a ser feito conforme as características morfológicas, dando origem a grupos, isto é, as denominadas "raças". Outra referência obrigatória é a que no Brasil determinados tracos físicos, principalmente o tipo de cabelo e de cor da pele, foram os elementos utilizados pelas principais formas de discriminação. Em outras palavras, em vez de um preconceito de origem em que o negro é descendente de família negra, observou-se o que Oracy Nogueira (1955) nomeou de preconceito de marca.

Há que salientar, por outro lado, que no contexto brasileiro o termo raça não corresponde aos conceitos delineados na antropologia física. Cuida-se de uma definição que tem por critérios traços fenotípicos e sociais. Nessa perspectiva, a cor assume uma função social, com a preferência pelo modelo "branco/europeu". Também se poderia cogitar aqui, numa certa negociação em torno da raça, o que nos remete ao exemplo citado pela autora Schwarcz (1998), envolvendo uma professora universitária que, em pesquisa pelo censo, percebeu que sua raça foi anotada como branca e, ao se insurgir, foi questionada pelo pesquisador: "Mas a senhora não é professora da USP?".

É justamente nesse sentido que se formou a sociedade contemporânea, basicamente dividida em três grupos socioeconômicos. No plano mais elevado da população, há uma elite, que condiz com o antigo grupo dos "brancos-ricos", e uma classe média, está formada, predominantemente, por brancos e mestiços ligados a ocupações "não manuais" e renda média. Já no plano considerado inferior, uma classe pobre, constituída, em regra, por pretos e mestiços escuros dedicados às ocupações braçais e inferior nível econômico (AZEVEDO, 1966).

Importa salientar, ainda, que a doutrina tradicionalmente tem distinguido a importância da cor a depender do contexto. Trata-se, em síntese, do que Lívio Sansone (2003) apontou como áreas moles e áreas duras nas relações raciais. Nas áreas vinculadas ao domínio do lazer e à religião (áreas moles), possui a cor menor relevância, ao passo que, nas áreas principalmente vinculadas ao trabalho e ao matrimônio (áreas duras), assume a cor maior relevância. Fazendo-se a devida vinculação, é necessário consignar que o sistema de estratificação social tem sua hierarquia definida justamente em razão da inter-relação família, educação e trabalho, ou seja, nas ditas áreas duras. Não é, portanto, sem razão que se assenta que aqui a exclusão e subordinação de negros se estruturam. 
Outro aspecto que merece ser ressaltado em relação ao preconceito afeito à realidade brasileira, é que, ao contrário de muitos países, no Brasil, desde a república, não houve política discriminatória oficial, ao revés, o Estado passou a proibir qualquer discriminação racial. Nessa perspectiva, como bem sustentado pela já citada autora Schwarcz (1998), a sociedade assumiu entornos de uma "boa consciência", negando o preconceito e remetendo ao plano pessoal eventual conflito de raça. Não por outro motivo, conforme exemplifica a mesma autora, em pesquisa realizada na cidade de São Paulo em 1988, 97\% dos entrevistados negaram possuir preconceito, mas, de outro lado, $98 \%$ afirmaram conhecer alguém que tem preconceito.

Igualmente reveladores são os resultados obtidos em um estudo sobre as atitudes sociais das crianças em relação ao negro, mediante a aplicação de um jogo com duas bonecas iguais, mas com cores diferentes (uma delas branca e a outra preta), e interpretação de quadros correspondentes a cenas da vida. Neles, percebeu-se que há, entre todos os examinandos, independentemente da cor e meio social, uma preferência pelos brancos. Pelas crianças brancas, com frequência, foram atribuídos aos pretos um lugar secundário e um papel social inferior. Já entre as crianças de cor, embora mantido o ideal branco, raramente se verificou a atribuição de papel inferior aos negros (BASTIDE \& FERNANDES, 1955).

Além dessas considerações à luz da teoria, há que fazer referência a dados estatísticos que, ao longo de décadas, evidenciam a desigualdade sofrida por negros e pardos em comparação com brancos (ou não negros). Nesse sentido, a Pesquisa Nacional por Amostra de Domicílios (PNAD), em 1976, comprova rendimento médio de negros em valor inferior ao rendimento médio dos brancos, resultado ratificado pelos dados de 1996, que, inclusive, evidencia uma diferença equivalente a mais que o dobro. Mais preocupante ainda é o fato que dados têm demonstrado que a diferença vem se mantendo estável ou, no máximo, com mínima redução. A exemplo dos resultados obtidos pelo Instituto de Pesquisa Econômica Aplicada - IPEA (2008), com base nos dados do IBGE, ao constatar que, no período de 1982 a 1999, a desigualdade se manteve estagnada (em torno 2,4 ) e, entre 2001 a 2008, houve pequena redução, a qual, se mantida nesse ritmo, igualdade de renda média apenas ocorrerá em 2040. Essa conclusão é ratificada pelo censo de 2010, o qual revela diferença salarial em torno 2,4 vezes.

Da mesma forma, em procedendo a uma comparação, a população negra possui taxa de desemprego mais elevada e média de tempo maior para recolocação no mercado de trabalho, segundo se extrai do mapa da população negra no mercado de trabalho realizado pelo Instituto Sindical Interamericano pela Igualdade Racial. Associado a isso, dados do IBGE correspondentes à pesquisa censitária de 2009, mostram que a posição de empregador é ocupada por 6,1\% dos brancos, $1,7 \%$ dos pretos e $2,8 \%$ dos pardos, ao passo que trabalhos domésticos e informais são ocupados, predominantemente, por negros e pardos.

No que tange à educação, há resultados igualmente alarmantes. A Pesquisa Nacional por Amostra de Domicílio (PNAD) de 1996 comprova significativa diferença em relação ao nível médio de escolaridade (brancos 6,25 anos, pardos é de 3,96 e entre pretos é de 3,81\%), sendo que tais diferenças se mantiveram quase inalteradas ao longo das últimas gerações. Pior, no que toca ao acesso ao ensino superior, consoante resultados obtidos pelo estudo alusivo aos 120 anos após a abolição, realizado pelo Instituto de Pesquisa Econômica Aplicada IPEA (2008), a situação se agravou, visto que, em relação aos percentuais referentes aos alunos que haviam concluído o curso superior, identificou-se um hiato de 4,3 em 1976 e de 13 pontos em 2006.

Os dados ora apresentados são suficientes para demonstrar que a desigualdade racial sobreviveu ao longo dos anos e se faz presente no âmbito da sociedade moderna. Dito isso, a questão que desponta diz respeito às causas dessa desigualdade. Será apenas uma herança do período escravocrata? 
A desigualdade social no Brasil normalmente tem sua explicação consubstanciada numa espécie de "sobrevivência da escravidão" ou "herança da pobreza". Isto é, o indivíduo de cor é, atualmente, pobre porque é descendente de uma família que também era pobre. Embora seja essa uma explicação necessária, não é, entretanto, uma explicação suficiente. Isso porque as desigualdades também são produzidas por aquilo que a doutrina denominou de "ciclos de desvantagens cumulativas" (SILVA, 2000).

Em linha semelhante de raciocínio, Carlos Hasenbalg (1979) afirma que a desigualdade entre brancos e negros não decorre apenas de questões ligadas à origem dessas populações. As oportunidades desiguais de ascensão e o racismo contemporâneo são fatores que contribuíram significativamente para isso. Como importante circunstância que contribuiu para esse desiquilíbrio, o autor também ressalta a política de imigração de "matizes racistas", que ensejou a marginalização e concentração dos negros em regiões menos desenvolvidas, principalmente no Nordeste.

\section{O direito à igualdade racial}

Em âmbito internacional, embora a proteção dos direitos humanos tenha se voltado, inicialmente, para uma proteção geral e abstrata, percebeu-se a necessidade de uma proteção especial para alguns grupos mais vulneráveis, como negros e as mulheres. Aqui assume relevo a Convenção sobre a Eliminação de todas das formas de Discriminação Racial, adotada pelas Nações Unidas em 1965, em que os Estados-partes se comprometeram a adotar não só políticas para eliminação da discriminação racial, mas também voltadas para a promoção da igualdade, sob a conviç̧ão de que a mera atuação de caráter repressivo-punitivo, por si só, não basta, sendo imprescindível, em ato conjunto, promover a inclusão de grupos socialmente vulneráveis (PIOVESAN, 2005).
Na esteira das revoluções francesa e americana do final do século XVIII, o Brasil adotou a igualdade perante a lei ainda na Constituição Imperial Outorgada de 1824 (SISS, 2003). E, com advento da República, o preceito constou na Constituição de 1891 e se manteve nas constituições subsequentes, igualmente pelo enforque formal, até a promulgação da Constituição de 1988 quando houve a transição, segundo Mello (2002), de uma "igualização estática" para uma "igualização eficaz, dinâmica".

Adotou a Carta Magna de 1988, portanto, o princípio da igualdade de direitos, garantindo a todos o direito de tratamento idêntico perante a lei, conforme critérios previstos no ordenamento jurídico. É o que a doutrina tradicional define como igualdade de aptidões e de possibilidades virtuais. Isso, contudo, não significa que a ordem constitucional não admita tratamentos desiguais, ao revés, o princípio da igualdade pressupõe tratamento desigual para indivíduos em situações diferentes, o que não se admite é a diferenciação de forma arbitrária (MORAES, 2006). A propósito, é com base no princípio da igualdade que muitos justificam a necessidade de distribuição de postos de trabalho e de vagas nas universidades como forma de favorecer quem se encontra em desvantagem (SINGER, 2006).

\section{Medidas de Ação Afirmativa}

A definição de ações afirmativas pode ser extraída da Convenção internacional sobre a eliminação de todas as formas de discriminação racial, adotada pela Resolução n. ${ }^{\circ}$ 2.106-A da Assembleia das Nações Unidas, em 21 de dezembro de 1965 e ratificada pelo Brasil em 27 de março de 1968:

\footnotetext{
[...] medidas especiais e concretas para assegurar como convier o desenvolvimento ou a proteção de certos grupos raciais de indivíduos pertencentes a estes grupos com o objetivo de garantir-lhes, em condições de igualdade, o pleno exercício dos direitos do homem e das liberdades fundamentais.
} 
Há que consignar que as medidas de ação afirmativa são justificadas por vários argumentos. Contudo, o principal fundamento está na justiça distributiva, isto é, na necessária distribuição equitativa dos bens escassos na sociedade. Em síntese, significa dizer que as medidas de ação afirmativa encontram justificativa na necessária distribuição equitativa dos bens escassos na sociedade. Nesse sentido, refere Gomes (2001, p. 68):

[...] a ação afirmativa define-se como um mecanismo de 'redistribuição' de bens, benefícios, vantagens e oportunidades que foram indevidamente monopolizados por um grupo em detrimento de outros, por meio de um artifício moralmente e juridicamente condenável - a discriminação.

Para muitos, a ação afirmativa na acepção atual teve origem na Índia, no denominado sistema de reservations. Isso porque, desde a primeira constituição do país, em 1948, foram adotadas medidas especiais destinadas aos Dalits ou Intocáveis, principalmente voltadas para a promoção do acesso ao parlamento, ao ensino superior e ao funcionalismo público (SILVA, 2003).

No entanto, grande parte das características e limitações das ações afirmativas foram traçadas nas políticas implementadas pelo governo norte-americano a partir de meados do século XX em razão de movimentos de reivindicações pelos direitos civis. Trata-se, segundo leciona Wedderburn (2005, p. 318), do "primeiro país do 'primeiro mundo' a incorporar à sua legislação e prática social mecanismos surgidos do contexto geral de descolonização do mundo afro-asiático, no intuito de emancipar um segmento subalternizado".

Mesmo após a abolição, negros e brancos viviam em mundos à parte. Aliás, essa segregação passou a ter respaldo com o julgamento proferido pela Suprema Corte americana ao apreciar o caso Plessy v. Ferguson em 1896. $\mathrm{Na}$ oportunidade, Plessy havia se negado a viajar entre os negros porque se considerava branco, uma vez que dispunha em seu sangue apenas $1 / 8$ de ascendência negra e todo o restante, $7 / 8$, de caucasiana), o que resultou na sua prisão. Ao apreciar o caso, a Corte declarou a constitucionalidade do Estatuto da Louisiana que permitia o transporte em vagões separados pela raça, sob o fundamento de que a mera separação em espaços físicos não configuraria a inferioridade de uma raça perante outra. Segundo constatou a Corte, a distinção visava à preservação da paz e a ordem pública (BOTELHO, 2010).

Por certo, a atuação da Suprema Corte dos Estados Unidos foi fundamental na formatação e consolidação das ações afirmativas. Um marco importante foi o julgamento proferido no caso Brown v. Boar of Education of Tapeka. Nesse, a Corte Suprema declarou inconstitucional a lei do Estado de Kansas que autorizava a criação de escolas separadas para negros e brancos. No entendimento da Corte, seria inaplicável na educação o ditame "separados, mas iguais", dado que essa segregação causaria manifestos prejuízos (BOTELHO, 2010).

Outro importante antecedente histórico é o emblemático caso Regents of University of California v. Bakke, julgado pela Suprema Corte norte-americana em 1978. A Faculdade de Medicina da Universidade da Califórnia mantinha um programa de ação afirmativa, com a reserva de vagas a negros e outras minorias, na razão de 16 a cada 100 vagas. Alan Bakke, candidato branco, foi reprovado no concurso, apesar de ter obtido nota superior aos candidatos que concorreram pelo sistema de cotas, motivo pela qual recorreu à Suprema Corte sob a alegação de tratamento discriminatório. Muito embora tenha considerado ilegal adotar a raça como único critério, definiu que não haveria óbices para ela também ser adotada como critério, desde associada a outros (SINGER, 2006).

Ao longo dos anos, percebeu-se um "ziguezague" das decisões da Suprema Corte no tocante às ações afirmativas. Gomes (2001) sistematiza essa variação em três fases. A primeira, na década de 1970, foi caracterizada pela indecisão 
acerca da validade, características e limites das ações afirmativas. A segunda, na década de 1980, foi marcada pela aprovação das medidas. E, a terceira, a partir do final da década de 1980, marcada pela restrição gradativa. Essa restrição às políticas de ação afirmativa também pode ser verificada no âmbito do legislativo norte-americano, inaugurada pela Proposition 209, lei aprovada por plebiscito em 1996, pela qual se proibiu a aplicação de medidas de ação afirmativa pelo governo do Estado da Califórnia (GOMES, 2001).

Por inspiração do exemplo norte-americano que muitos países adotaram medidas de ações afirmativas. $\mathrm{Na}$ verdade, enquanto se iniciava uma restrição gradativa nos Estados Unidos, ocorria uma expressiva ampliação das medidas pelo mundo. Além do mais, houve, inclusive nos Estados Unidos, uma expansão do conceito de grupos minoritários. Isto é, embora as medidas afirmativas na origem estivessem apenas destinadas a grupos quantitativamente minoritários, os negros norte-americanos, mais tarde esse conceito foi ampliado, passando a abranger também grupos quantitativamente maiores, a exemplo das mulheres (SILVA, 2003).

No Brasil também se observou os efeitos da força expansiva das ações afirmativas. A criacão dessas medidas no Brasil seguiu referências da proteção verificada em âmbito internacional. Fora a Convenção Internacional sobre a Eliminação de todas as Formas de Discriminação Racial, o Brasil ratificou outras importantes normas internacionais em torno desse tema, tais como a Carta de Paris (1990) e o Pacto de San José da Costa Rica (1993). No âmbito jurídico interno, além da Carta Magna de 1988, vários diplomas passaram a contemplar a proteção de setores sociais, sobretudo mulheres e portadores de deficiência (AMARO, 2015).

Em relação à Integração social étnica e racial, avanços importantes foram observados a partir da década de 1990, mas o divisor de águas foi a participação do Brasil na III Conferência Mundial das Nações Unidas de Combate ao Racismo, Discriminação Racial, Xenofobia e Intolerância Correlata, realizada no ano de
2001 em Durban/África do Sul. Na oportunidade, a proposta enviada pela delegação brasileira a essa conferência trouxe as ações afirmativas como medidas a serem adotadas em benefício da população negra, inclusive a reserva para o acesso ao ensino superior (FRY e MAGGIE, 2004).

No tocante ao ensino superior, há de se destacar ainda a Medida Provisória $n^{\circ}$ 213/2004, posteriormente convertida na Lei $n^{\circ} 11.096 / 05$, que se instituiu o Programa Universidade para Todos - PROUNI, com a concessão de bolsas de estudo em instituições privadas de ensino superior, bem como a Lei $n^{\circ} 12.711 / 12$, que, por sua vez, instituiu a reserva de vagas nas instituições federais de educação superior.

Antes mesmo da referida imposição legal no plano das instituições federais de ensino superior, o sistema de cotas já havia sido inaugurado em âmbito estadual. A propósito, em 09 de novembro de 2001 o Rio de janeiro editou a Lei $n^{\circ} 3708$, reservando aos negros e pardos $40 \%$ das vagas oferecidas pela Universidade do Estado do Rio de Janeiro (UERJ) e pela Universidade Estadual do Norte Fluminense Darcy Ribeiro (PENA \& BOTOLINI, 2004).

Por fim, importa destacar que os programas de ação afirmativa que estabelecem sistema de reserva de vagas, com base em critério étnico-racial, para acesso ao ensino superior foi objeto de exame pelo Supremo Tribunal Federal, nos autos da Arguição de Descumprimento de Preceito Fundamental (ADPF) de $n^{\circ}$. 186, ajuizada pelo partido Democratas, vindo a Corte a decidir pela validade desses sistemas.

\section{Debate sobre As Cotas para Negros nas Universidades}

Há quem sustente argumentos em sentido contrário à adoção dessas medidas, sobretudo em relação às reservas de vagas com base em critério racial. Não obstante, comungamos do entendimento de que tais argumentos ou são inaplicáveis ao caso brasileiro ou são, por motivos diversos, insuficientes para, por si só, impedir que sejam adotadas as medidas de ação afirmativa. 
Nessa perspectiva, sem a pretensão de esgotamento e aprofundamento, convém uma revisão dos principais argumentos de oposição a essas medidas. De início, há que se afastar o argumento de que tais medidas resultam numa penalização de indivíduos inocentes, ou "branco inocente" pela expressão norte-americana. Isso porque, como bem sustentado por Takaki (1994), a discriminação positiva para os brancos esteve presente ao longo de anos, sendo que os bens que atualmente são objeto de restrição possivelmente só foram obtidos pelas vantagens e oportunidades que aos brancos foram asseguradas ao longo desses anos e, no mais, repassadas e cumuladas à medida que transmitidas entre as gerações.

Da mesma forma, há que se rechaçar o argumento de oposição segundo o qual as desigualdades são resultantes de fatores econômicos e, portanto, esse deverá ser o critério adotado para fins de medidas de ação afirmativa. Nesse contexto, ousando divergir da posição, compartilhamos do entendimento de que essa vinculação é imprópria. Como bem realça Maliska (2001), as políticas raciais são instituídas por fundamentos próprios e com objetivos particulares, como, por exemplo, o combate à discriminação racial. Há que se observar que, diferentemente dos demais grupos que também ocupam elevados níveis de pobreza, os negros foram alçados a essa condição por motivos peculiares, notadamente a segregação do regime escravocrata e a dificuldade de mobilidade social por conta do racismo.

De plano, também não merece prosperar o argumento de oposição que reside na dificuldade de se identificar o indivíduo negro diante da miscigenação brasileira. Isso porque a discriminação, por si só, comprova que é possivel identificar o indivíduo negro. Com efeito, recoIhendo-se aqui a lição de Medeiros (2005, p. 129): "Afirmar que não se pode fazer ação afirmativa no Brasil porque é impossível distinguir quem é negro ou branco é sustentar o paradoxo de que algo é ao mesmo tempo possível e impossível".
Além disso, no tocante ao argumento de que as medidas de ação afirmativa violam o princípio do mérito, partilhamos o entendimento no sentido contrário. Trata-se, na verdade, de meio para tornar o critério de seleção mais justo, ao levar em conta, além do resultado, fatores essenciais como a capacidade de superar obstáculos. Do contrário, é permitir que o acesso ao ensino superior seja um privilégio dos poucos, sobretudo de quem frequentou as melhores escolas e pagou os mais caros cursos preparatórios (TELLES, 2003).

Por fim, não merece prosperar o argumento de que antes de se garantir o ingresso desses alunos nas universidades se faz necessário oferecer um ensino público de qualidade no nível médio. Com efeito, as iniciativas para garantir o acesso ao ensino superior devem se fazer acompanhar de investimentos no ensino médio de modo a preparar os futuros candidatos às vagas universitárias. No mais, parece viável pensar, inclusive, em novas formas de seleção para o ingresso nas universidades, como, por exemplo, a valorização do desempenho escolar no ensino médio e a avaliação ao final de cada ano letivo. De qualquer modo, não se deve esquecer a já referida necessidade de medidas com efeitos imediatos, pois, ao contrário, o jovem negro permanecerá por mais algumas gerações sem acesso ao ensino universitário (OLIVEN, 2006).

\section{O Levantamento de Alguns Resultados Práticos}

A permanente atualidade do tema decorre não apenas da necessidade de reavaliar-se a farta e excelente produção doutrinária, mas também de verificar-se a eficácia social dos instrumentos jurídico-políticos disponíveis. Em outras palavras, trata-se de procurar as respostas para indagação em torno da efetividade das medidas de ação afirmativa. Não por outro motivo, há que se ocupar, neste item derradeiro, de uma análise, ainda que superficial, de alguns resultados até então obtidos. 
Desde logo, convém que se lance um breve olhar sobre o direito comparado. Isso porque não se pode olvidar que da experiência, ainda que seja de um modelo não similar ao pátrio, pode-se extrair interessantes subsídios para o equacionamento do problema. É nesse sentido que assume relevância o estudo promovido pelo Programa das Nações Unidas pelo Desenvolvimento - PNUD, em que são examinadas as experiências de vários países, inclusive alguns com longa história de ação afirmativa, como Índia, Malásia e Estados Unidos, senso constatado que as políticas de ação afirmativa têm tido êxito na realização de seus objetivos.

Em relação aos programas de reservas de vagas em funcionamento no contexto brasileiro, há que destacar que, ao menos em números isoladamente considerados, houve a ampliação do acesso de negros ao ensino superior. Esse indicativo se extrai, por exemplo, da análise comparativa entre os dados apurados nos anos de 2001 e 2011 pela Pesquisa Nacional por Amostragem, dado que a frequência, de 10,2\% em 2001, passou a 35,8\% em 2011. Saliente-se, aqui, que a distinção ora referida, porém, não é apenas um reflexo das medidas de ação afirmativa, mas também inclui outros fatores, principalmente a expansão da educação superior que ocorreu no Brasil ao longo desse período (IBGE, 2012).

Em uma análise do impacto no âmbito da Universidade Federal da Bahia, levando-se em conta os dados do ano de implementação (2005) e os dados do ano anterior (2004) no que diz respeito aos cursos de maior prestígio e concorrência, percebe-se uma realidade bastante animadora. Em 2004, o quadro de aluno da universidade estava formado por brancos $(42,2 \%)$, pardos $(46,7 \%)$ e pretos $(8,1 \%)$. Ao passo que, no ano seguinte, com a implementação das medidas, esse mesmo quadro passou a ser representado por bran$\cos (25,3 \%)$, pardos $(60 \%)$ e negros $(13,0 \%)$. De irrefutável importância referir, entretanto, que em relação aos negros se observou nos anos seguintes uma oscilação, inclusive retornando-se ao mesmo percentual de 2005. Assim, em
2006 (11,3\%), em 2007 (12,8\%), em 2008 (14,7\%), em 2009 (14,0\%), em 2011 (15,9\%) e, por fim, em 2012 (13,0\%) (SANTOS \& QUEIROZ, 2013).

Ainda nesse contexto, há que destacar os resultados obtidos na universidade Estadual de Londrina. No ano de 2004, o contingente da universidade estava formado $78,4 \%$ de alunos brancos e apenas $13,2 \%$ de estudantes negros. Após o início do sistema de cotas, em 2005, o percentual de negros subiu para $18,2 \%$, no ano de 2008 , atingiu $20 \%$ e, em 2012 , caiu para $17,7 \%$. É necessário, contudo, atentar que, aqui, a categoria negro é constituída pela soma de pretos e pardos (SILVA \& PACHECO, 2013).

Inegável impacto igualmente se observou no sistema adotado pela Universidade Federal do Rio Grande do Sul a partir do ano de 2008, em que houve a reserva de $30 \%$ das vagas para alunos que cursaram em escolas públicas o ensino fundamental (ao menos metade) e a integralidade do ensino médio, sendo que metade dessas vagas são voltadas aos candidatos autodeclarados negros. O percentual de negros, aqui incluindo pretos e pardos, oriundos de escolas públicas passou de 3,6\% a 11,6\% entre os anos de 2007 e 2008. Na comparação entre pretos e pardos egressos do ensino público, nota-se um melhor resultado referente aos pretos. Nos anos entre 2007 a 2008, a proporção de aprovados pardos foi de $2,6 \%$ para $5,2 \%$, enquanto a de pretos passou de 1,0\% a 6,4\% no mesmo período. Ainda, há que referir que, no período anterior à implementação do sistema de cotas, os alunos oriundos de escolas públicas se mostravam divididos entre pretos e pardos de forma quase proporcional aos respectivos percentuais encontrados na população do Estados, segundo dados do censo de 2010. Nos anos seguintes, no entanto, entre os egressos de escolas públicas aprovados, o número referente a pretos foi superior ao número corresponde aos pardos (MONSMA, SOUZA \& SILVA, 2013).

De positivo, importa citar ainda o impacto verificado na universidade Federal de Santa Catarina. Isso porque, antes da implementação da ação afirmativa, período entre 2004 e 2007, pretos e pardos representavam 1\% e 7,5\%, 
respectivamente, dos alunos da universidade. Com a implementação, a partir de 2008, os percentuais passaram para $4,6 \%$ de pretos e $8,8 \%$ de pardos. Em outras palavras, houve um crescimento de 3,6\% em relação aos pretos e 1,3\% em relação aos pardos (TRAGTENBERG, BOING, BOING \& TASSINARI, 2013).

\section{Considerações Finais}

O que se conclui do exposto é que a adoção de medidas de ação afirmativa, inquestionavelmente, contribuiu e vem contribuindo para maior diversidade social e racial no âmbito de inúmeras sociedades ao redor do mundo e ao longo da história. É o que se percebe, ao menos em preliminar análise, pelo novo perfil populacional que passou a integrar os quadros de ensino superior no sistema brasileiro.

Em que pese se tratar de pequena representação, se considerarmos o número significativo de universidades em funcionamento no país, inegáveis e percebidos são os resultados relevantes, pois, de fato, há dados que comprovam o aumento no percentual de negros no interior das universidades. Por certo, não há como negar que outros fatores contribuíram para essa repercussão, como a já referida expansão da educação superior no Brasil ao longo dos últimos anos.

Em se levando em conta essa contribuição, ainda que em reduzido grau, à efetiva redução das desigualdades, pode-se afirmar, sem receio de errar, que tais medidas não poderão ser suprimidas ou restringidas sem uma válida reflexão e insistentes tentativas de implementação, sob pena de um indesejável retrocesso. Em última análise, no tradicional embate entre adeptos dessas políticas de feição social intervencionista e aqueles de manifesta oposição, há que se manter de forma inegociável o ideal de igualdade substancial entre todos os integrantes do corpo social, independentemente de fenotipia, cor ou outro elemento distintivo.

\section{Referências}

AMARO, S. (2015). Racismo, igualdade racial e políticas de ações afirmativas no Brasil. Porto Alegre: EDIPUCRS.

ARAÚJO, R. B. (1994). Guerra e Paz: Casa-grande senzala e a obra de Gilberto Freyre nos anos 30. Rio de Janeiro: 34 Letras.

AZEVEDO, T. (1966). Cultura e situação racial no Brasil. Rio de Janeiro: Editora Civilização Brasileira S.A.

BASTIDE, R. \& FERNANDES, F. (1955). Relações raciais entre negros e brancos em São Paulo. São Paulo: Editora Anhembi Limitada.

BOTELHO, M. C. (2010). A ação afirmativa e a questão das quotas raciais. Direitos Fundamentais e Justiça: Revista do Programa de Pós- Graduação, Mestrado e Doutorado em Direito da PUC-RS. Porto Alegre, v. 4, n. 13, p. 163-183, out./dez. 2010.

CARDOSO, F. H. (1997). Capitalismo e Escravidão no Brasil Meridional: o negro na sociedade escravocrata do Rio Grande do Sul. Rio de Janeiro: Paz e Terra.

FRY, P. \& MAGGIE, Y. (2002). A reserva de vagas para negros nas universidades brasileiras. In: USP Estudos avançados, dossiê o negro no Brasil (v. 18, n 50, jan/abr. 2004). São Paulo.

GOMES, J. B. B. (2001). Ação Afirmativa \& Princípio Constitucional da Igualdade: 0 direito como instrumento de transformação social. A experiência dos EUA. Rio de Janeiro: Renovar.

HASENBALG, C. A. (1979). Discriminação e desigualdades raciais no Brasil. Rio de Janeiro: Graal. MALISKA, M. A. (2001). O Direito à educação e a Constituição. Porto Alegre: Fabris.

MEDEIROS, C. A. (2005). Ação afirmativa no brasil: um debate em curso. In: SANTOS, S. A. (orgs). Ações afirmativas e combate ao racismo nas Américas. Brasília: Ministério da Educação, Secretaria de Educação Continuada, Alfabetização e Diversidade. 
MELLO, M. A. M. F. (2002). Óptica Constitucional A Igualdade e as Ações Afirmativas. In: Revista da EMERJ (v. 5, n. 18). Rio de Janeiro: EMERJ.

MONSMA, K.; SOUZA, J. V. S.; SILVA, F. O. (2013). As consequências das ações afirmativas na universidade Federal do Rio Grande do Sul: uma análise preliminar. In: SANTOS, J. T. (orgs.). O impacto das cotas nas universidades brasileiras (2004-2012). Salvador: CEAO. MORAIS, A. (2006). Direito Constitucional (20. Ed). São Paulo: Atlas S.A.

PENA, S. D. J. \& BOTOLINI, M. C. (2004) Pode a genética definir quem deve se beneficiar das cotas universitárias e demais ações afirmativas? In: USP Estudos avançados, dossiê o negro no Brasil v. 18, n.50, jan/abr. 2004). São Paulo.

PIOVESAN, F. (2005). Ações afirmativas sob a perspectiva dos direitos humanos. In: SANTOS, S. A. (orgs.). Ações afirmativas e combate ao racismo nas Américas. Brasília: Ministério da Educação, Secretaria de Educação Continuada, Alfabetização e Diversidade.

SANTOS, J. T. \& Queiroz, D. M. (2013). O impacto das cotas na universidade Federal da Bahia (2004-2012). In: SANTOS, J. T. (orgs.). O impacto das cotas nas universidades brasileiras (2004-2012). Salvador: CEAO

SANTOS, S. A. (1999). Ação afirmativa ou a utopia possível. In: Oliveira, D. D. (Org.) et al. 50 anos depois: relações raciais e grupos socialmente segregados. Brasília: Movimento Nacional de Direitos Humanos.

SCHWARCZ, L. M. (1998). Nem preto nem branco, muito pelo contrário: cor e raça na intimidade. In: História da vida privada no Brasil: contrastes da intimidade contemporânea. São Paulo: Companhia das Letras.
SILVA, C. (2003). Ações afirmativas em educação: experiências brasileiras. São Paulo: Summus.

SILVA, H. (2000). Extensão e natureza das desigualdades raciais no Brasil. In: GUIMARÃES, A. \& HUNTLEY, L. (orgs.). Tirando a Máscara: ensaios sobre o racismo no Brasil. São Paulo: Paz e Terra. SILVA, M. N. \& PACHECO, J. Q. (2013). As cotas na universidade Estadual de Londrina: balanço e perspectivas. In: SANTOS, J. T. (orgs.). 0 impacto das cotas nas universidades brasileiras (2004-2012). Salvador: CEAO.

SINGER, P. (2006). Ética aplicada (3. Ed.). São Paulo: Martins Fontes.

SISS, A. (2003). Afro-brasileiros, cotas e ação afirmativa: razões históricas. Rio de Janeiro: PENESB.

SKIDMORE, T. (1976) Preto no branco (Raul de Sá Barbosa, Trad). Rio de Janeiro: Paz e Terra. (Original work published 1974).

SOWELL, T. (2004). Affirmative Action Around the World: an Empirical Study. New Haven: Yale University Press.

TELLES, E. (2003). Racismo à brasileira: uma nova perspectiva sociológica. Rio de Janeiro: Relume Dumará.

TRAGTENBERG, M. H. R.; BOING, A. C.; BOING, A. F.; TASSINARI, A. M. I. (2013). Impacto das ações afirmativas na universidade Federal de Santa Catarina (2008-2011). In: SANTOS, J. T. (orgs.). O impacto das cotas nas universidades brasileiras (2004-2012). Salvador: CEAO.

WEDDERBURN, C. M. (2005). Do marco histórico das políticas públicas de ação afirmativa. In: SANTOS, S. A. (orgs.). Ações afirmativas e combate ao racismo nas Américas. Brasília: Ministério da Educação, Secretaria de Educação Continuada, Alfabetização e Diversidade. 
